\title{
Evaluation of Service Life of Jointed Rails
}

\author{
Hiroo KATAOKA \\ Assistant Senior Researcher, \\ Noritsugi ABE \\ Senior Researcher, Laboratory Head, Assistant Senior Researcher, \\ Track Structures \& Components, \\ Track Technology Div.

\section{Osamu WAKATSUKI}

\begin{abstract}
The service life of jointed rails is governed mainly by the fatigue fracture at the joints. Static loading tests and field tests were carried out to measure the stresses around fish bolt holes. Based on these results and FE analysis, we developed a method to evaluate the stresses at the edges of fish bolt holes when fish bolts were fastened and trains passed. An $S-N$ curve of rails with bolt holes was obtained from the results of bending fatigue tests. As a result of this study, we established a method to evaluate the fatigue life of jointed rails.
\end{abstract}

Keywords : jointed rail, stress, fish bolt hole, service life

\section{Introduction}

Jointed rails are replaced periodically in Japan. Their service life is governed mainly by the fatigue fracture at joints. There are several types of fractures. In paticular, cracks used to initiate at fish bolt holes (Fig. 1). As vehicles have become more lightweight and the fracture of jointed rail has decreased in recent years, we consider that the period of replacement can be extended. To evaluate the fatigue life of jointed rails, it is necessary to clarify the stress field around fish bolt holes and the S-N curve of jointed rails. However, it is difficult to evaluate the stress field precisely because there is stress concentration around the fish bolt holes and fish bolts may contact the edges of holes. Thus, we carried out static loading tests in a laboratory, field tests to measure the stresses around the fish bolt holes, static stress analysis of jointed rails and bending fatigue tests of rails with bolt holes. Based on the study results, we developed a method to evaluate the fatigue life of jointed rails.

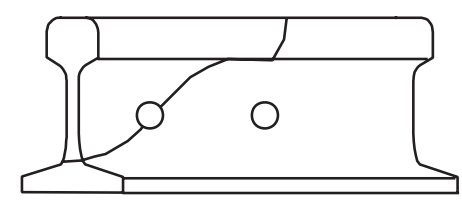

Fig. 1 Typical joint fracture

\section{Evaluation of stresses around fish bolt hole}

\subsection{Static loading tests}

Static loading tests were performed on a rail with nine sleepers. Figure 2 shows a skeleton of the test track. Sleepers were set on a rigid bed, pressed down by anchor bolts and sandwitched by ballast mats whose stiffness was $30 \mathrm{MN} / \mathrm{m}$. The rail was subjected to a static load of 100 $\mathrm{kN}$ in the vertical direction at intervals of $50 \mathrm{~mm}$ at the center of rail head in a section $-70 \mathrm{~mm}$ to $630 \mathrm{~mm}$ away from the rail end. Particulars of the test track structure are shown in Table 1. Tests were performed under sev- eral conditions shown in Table 2. The fastening torque in the cases 2 and 3 is the same as that in the case 1 . In the case 2 , the worn fishplates were made artificially by cutting the bottom ends and top middle of fishplate by 1 mm (Fig. 3). The condition of loose sleeper was set by inserting steel planes between the rail and sleepers. The tensile force of fish bolt was about $140 \mathrm{kN}$ with fastening torque at $500 \mathrm{Nm}$ and $70 \mathrm{kN}$ with fastening torque at 250

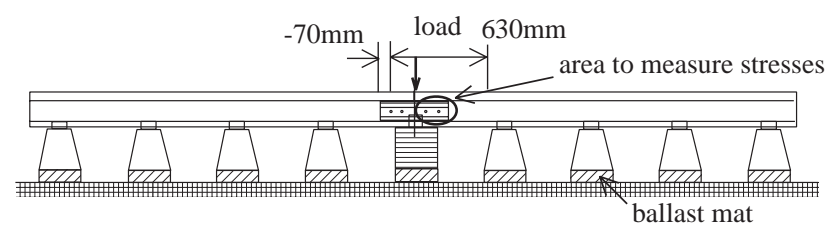

Fig. 2 Test track skeleton

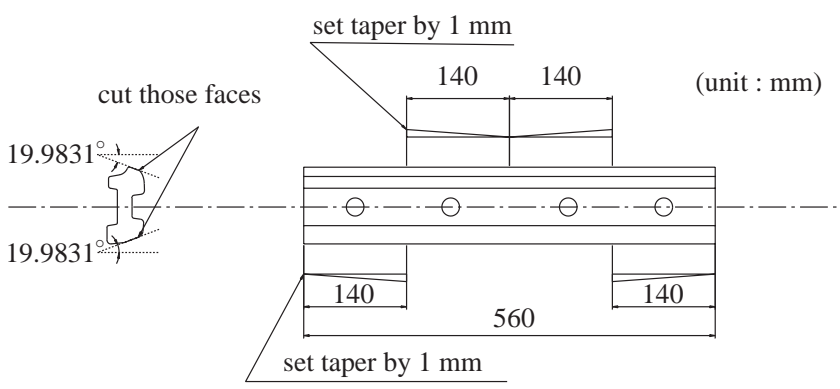

Fig. 3 Artificially made worn fishplate used in the tests

$x$ : Positions to measure stresses

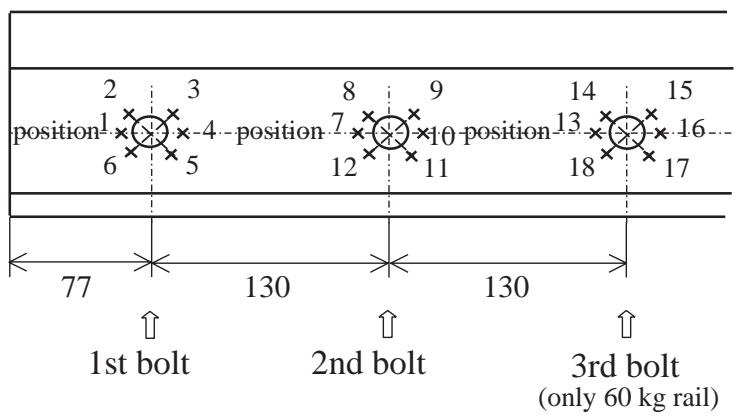

Fig. 4 Positions to measure stresses around fish bolt holes 
Table 1 Particulars of the test track (normal state)

\begin{tabular}{|c|c|c|}
\hline \multicolumn{2}{|c|}{ Item } & Specifications \\
\hline \multicolumn{2}{|c|}{ Rail type } & $50 \mathrm{kgN}$ rail \\
\hline \multirow{2}{*}{$\begin{array}{l}\text { Fastening } \\
\text { type }\end{array}$} & Joint & $\begin{array}{l}\text { Type for jointed rail } \\
\text { (for } 50 \mathrm{kgN} \text { ) }\end{array}$ \\
\hline & Other & Type 9 (for $50 \mathrm{kgN}$ ) \\
\hline \multicolumn{2}{|c|}{ Railpad stiffness } & $110 \mathrm{MN} / \mathrm{m}$ \\
\hline \multirow{2}{*}{$\begin{array}{l}\text { Sleeper } \\
\text { type }\end{array}$} & Joint & Wooden tie for joint \\
\hline & Other & PC sleeper type 6 \\
\hline \multicolumn{2}{|c|}{ Tie spacing } & $600 \mathrm{~mm}$ \\
\hline \multicolumn{2}{|c|}{ Ballast mat stiffness } & $30 \mathrm{MN} / \mathrm{m}$ \\
\hline \multicolumn{2}{|c|}{$\begin{array}{l}\text { Fastening torque of } \\
\text { fish bolts }\end{array}$} & $500 \mathrm{Nm}$ \\
\hline
\end{tabular}

Table 2 Test conditions

\begin{tabular}{|c|c|}
\hline Case & Condition \\
\hline 1 & Normal state (Table 1) \\
\hline 2 & Worn fishplate \\
\hline 3 & Loose sleeper \\
\hline 4 & Fastening torque at $250 \mathrm{Nm}$ \\
\hline 5 & Fastening torque at $50 \mathrm{Nm}$ \\
\hline 6 & $60 \mathrm{~kg}$ rail \\
\hline
\end{tabular}

$\mathrm{Nm}$. Stresses were measured at 0-degree and 45-degree positions to the longitudinal axis of rail $5 \mathrm{~mm}$ away from the edge of fish bolt hole by using three-axle strain gauges (Fig. 4). They were measured on the both sides of rail web.

Figure 5 shows the maximum principal stresses of 50 $\mathrm{kgN}$ rail when joint bolts were fastened. A tensile stress field occurred in the vertical direction because wedges were driven into the rail. The maximum value of maximum principal stresses averaged over diagonal positions was seen at 0 -degree positions of the 1 st bolt hole. That value was $218 \mathrm{~N} / \mathrm{mm}^{2}$ with torque at $500 \mathrm{Nm}$ and $124 \mathrm{~N} /$ $\mathrm{mm}^{2}$ with torque at $250 \mathrm{Nm}$. The maximum average stress with torque at $50 \mathrm{Nm}$ was less than $30 \mathrm{~N} / \mathrm{mm}^{2}$. In the case of worn fishplates, the average stresses were larger at positions between the 1st and the 2nd bolt hole and smaller at other positions than those in the normal state.

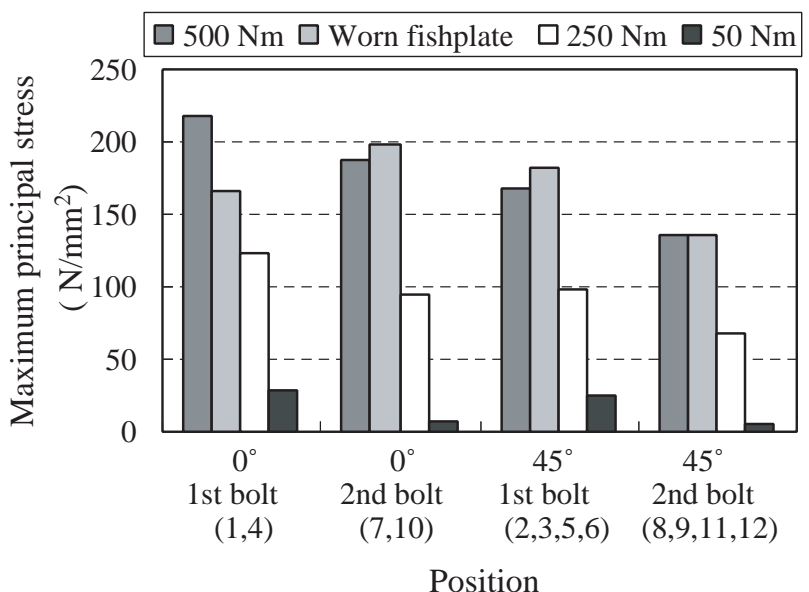

Fig. 5 Maximum principal stresses around holes with fastening
Figure 6 shows the maximum principal stress amplitudes under a vertical load with the stress set at 0 when joint bolts were fastened. The maximum amplitude of maximum principal stress occurred at 45-degree positions. This means that the rail fracture tends to occur at 45degree positions rather than at 0 -degree positions. The maximum amplitude was $34 \mathrm{~N} / \mathrm{mm}^{2}$ with torque at 500 $\mathrm{Nm}, 52 \mathrm{~N} / \mathrm{mm}^{2}$ with worn fishplates and $60 \mathrm{~N} / \mathrm{mm}^{2}$ with torque at $50 \mathrm{Nm}$. In the other two cases, the amplitudes were nearly equal to those with torque at $500 \mathrm{Nm}$.

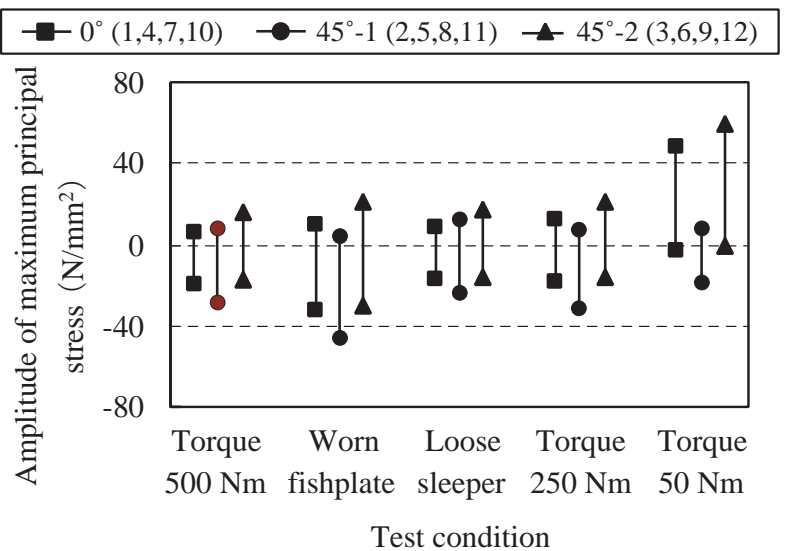

\section{Fig. 6 Maximum principal stress amplitudes under vertical loading}

The maximum value of maximum principal stresses averaged over diagonal positions of $60 \mathrm{~kg}$ rail when joint bolts were fastened was $116 \mathrm{~N} / \mathrm{mm}^{2}$ at 0 -degree positions of the 1 st bolt hole. It was less than the maximum stress of $50 \mathrm{kgN}$ rail because the contact style between $60 \mathrm{~kg}$ rail and fishplate was headfree and different from that of $50 \mathrm{kgN}$ rail. The effect of wedge was smaller than that of $50 \mathrm{kgN}$ rail. However, the amplitude of the maximum principal stress of $60 \mathrm{~kg}$ rail was $34 \mathrm{~N} / \mathrm{mm}^{2}$ at 45 -degree positions. It was nearly equal to that of $50 \mathrm{kgN}$ rail.

\subsection{Field tests}

Field tests were carried out on tangent and tight curves of radius $400 \mathrm{~m}$ of ballasted track of a narrowgauge line. We set several conditions on jointed rails, which were similar to those for the static loading tests in a laboratory. The condition of stepped joint was added. The torque of existing state was $250 \mathrm{Nm}$. The tests were carried out for limited express, local and freight trains. The stresses around fish bolt holes were measured in the circumferential direction at 45-degree positions $5 \mathrm{~mm}$ away from the hole edge. The wheel load and lateral force were measured at the position $12.5 \mathrm{~m}$ away from the joint.

We read the amplitudes between the maximum and minimum stresses on stress charts and clarified the relationship between the measured stress amplitudes and the vehicle speed, wheel load and lateral force under each condition by multiple regression analysis. We substituted the parameters averaged under each condition into the multiple regression equation and calculated the amplitudes of stresses. The results are shown in Fig. 7. The stress amplitudes around the end fish bolt hole of the 
oncoming side rail were larger than those obtained in the static loading test when a train passed because of the wheel load impact on the joint. The amplitudes of stress around the 1st bolt hole were large and the maximum was $89 \mathrm{~N} / \mathrm{mm}^{2}$ at the high rail of a tight curve with worn fishplates.

The results of the static loading tests and field tests indicate that the stress amplitudes with worn fishplates and small fastening torque were larger than those in the normal state and, therefore, the former two conditions tend to decrease the service life of jointed rails.

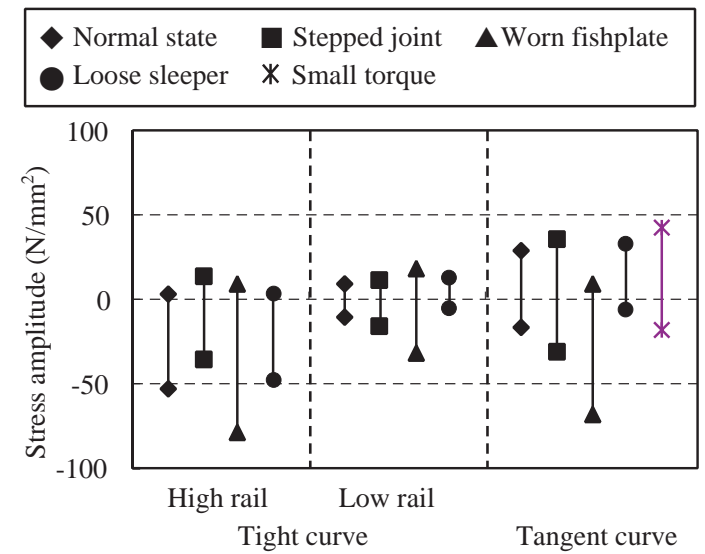

Fig. 7 Circumferential stress amplitude around bolt hole

\subsection{Static Analysis}

The behavior of jointed rails is complicated because the rail is in contact with fishplates. The stresses at positions $5 \mathrm{~mm}$ away from the edge of fish bolt holes (hereinafter referred to as "5 mm-positions") were measured. However, stresses at the edge of fish bolt holes need to be clarified. Stresses were calculated by FEM and compared with those measured in the static loading tests. Figure 8 (a) shows a whole finite element model of the track. Gap elements were used to idealize the contact between rail and fishplates. Railpads and the fastening device were modeled by using nonlinear spring elements. As the amplitude of axial forces of fish bolts were small in the static loading tests, axial forces were applied directly to the fishplates. Fine meshes were needed to express the stress concentration which occurred around fish bolt holes. For the analysis, we used the whole model first and then the fine mesh model around fish bolt holes for which the boundary condition was obtained from the displacements of the previous analysis. The fine model is shown in Fig. 8 (b). Analyses were carried out by using a NASTRAN FEM package.

Stresses were analyzed on the basis of parameters of the static loading tests (Table 1) and compared with those of the tests. The calculated maximum principal stress of $50 \mathrm{kgN}$ rail when bolts were fastened was smaller than the measured values. Thus, a larger load was applied to fishplates to make the stress occur to the extent of measured stresses. The difference in the amplitudes of the maximum principal stress calculated and measured at 5 $\mathrm{mm}$-positions was $17 \%$ of the maximum value and a simi- larity was achieved between these two values.

The relation of circumferential stresses at $5 \mathrm{~mm}$-positions with those at the hole edge was clarified by the analysis. Figure 9 shows a comparison between the

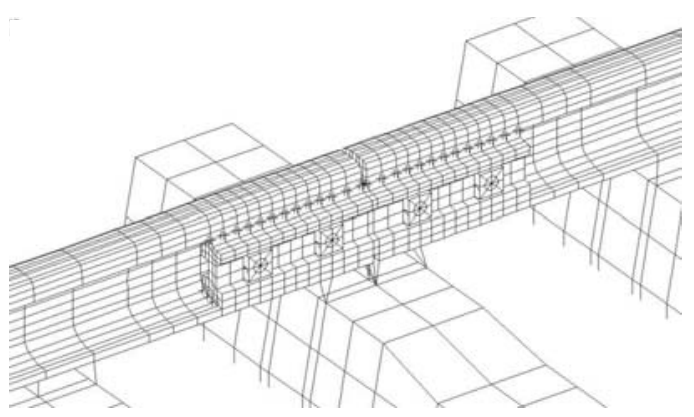

(a) Whole model

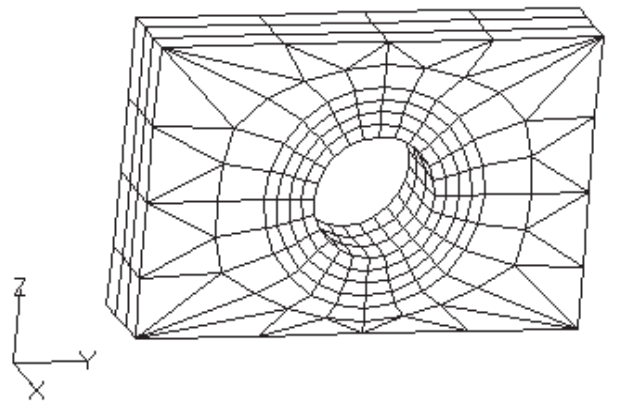

(b) Fine model around bolt hole

Fig. 8 Finite element model of jointed rail

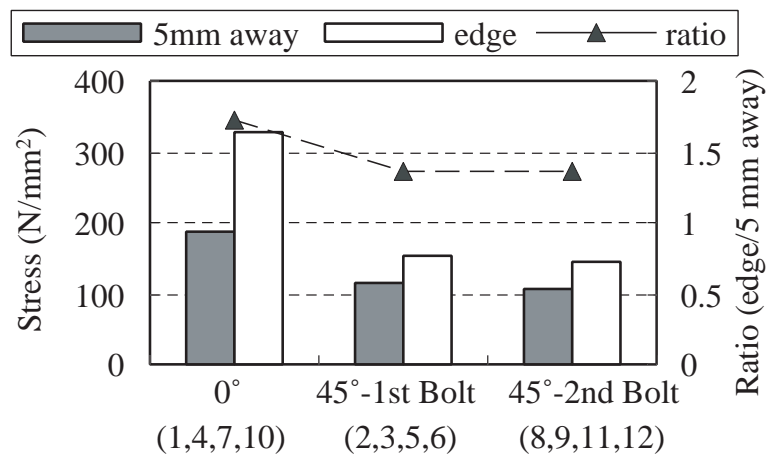

Position

(a) Stresses when bolts were fastened

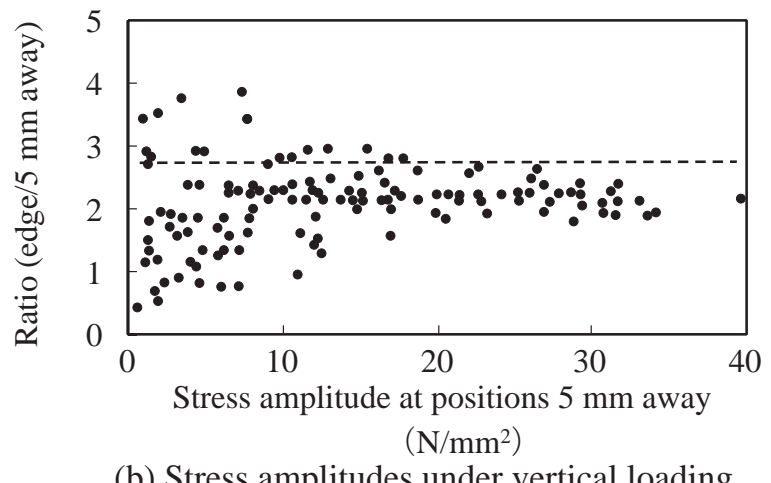

(b) Stress amplitudes under vertical loading

Fig. 9 Ratio between analyzed stress amplitudes at $5 \mathrm{~mm}$ away and those at the hole edge 
stresses at $5 \mathrm{~mm}$-positions and those at the edge. When joint bolts were fastened, the stresses at the edge were 1.73 times at the 0 -degree position and 1.37 times at the 45-degree position as large as those at $5 \mathrm{~mm}$-positions. Under a static load, most of the stress amplitudes at the edge were smaller than three times those at $5 \mathrm{~mm}$-positions. When the ratio was over 3 , the stress amplitudes were small and less than $30 \mathrm{~N} / \mathrm{mm}^{2}$ at the edge.

\subsection{Evaluation of stresses at fish bolt hole edge}

Based on the results, we established a method to evaluate the stresses at the edge of fish bolt hole when joint bolts were fastened and trains passed. The method is shown in Fig. 10. This method evaluates stresses under several conditions of jointed rail, vehicle type, vehicle speed, wheel load and lateral force. We calculate stresses at 45-degree positions at the edge of fish bolt hole when fish bolts are fastened by multiplying those at $5 \mathrm{~mm}$-positions obtained from static loading tests by the abovementioned ratio between the stresses at the edge and those at $5 \mathrm{~mm}$-positions. The stress amplitudes at $5 \mathrm{~mm}$ positions are calculated with the wheel load, lateral force and vehicle speed as parameters by using the multiple regression equation obtained from field tests. Those stress amplitudes are calculated for different vehicle types and joint conditions prescribed in section 2.2. We calculate the stress amplitudes under loading at the edge by multiplying the ratio by those at $5 \mathrm{~mm}$-positions. By adding these two stresses, we can obtain the absolute value of stress when trains pass.

In the case of $60 \mathrm{~kg}$ rail, we do not have field data of stress amplitudes. Then, we refer to the results of field tests of $50 \mathrm{kgN}$ rail. They are calculated by multiplying the result of static loading tests of $60 \mathrm{~kg}$ rail by the ratio of the result of field tests to that of static loading tests of $50 \mathrm{kgN}$ rail.

An example of stress is shown in Fig. 11. This data is for the position 6 in Fig. 4 of which stress amplitudes in the field tests were larger than those at other positions.

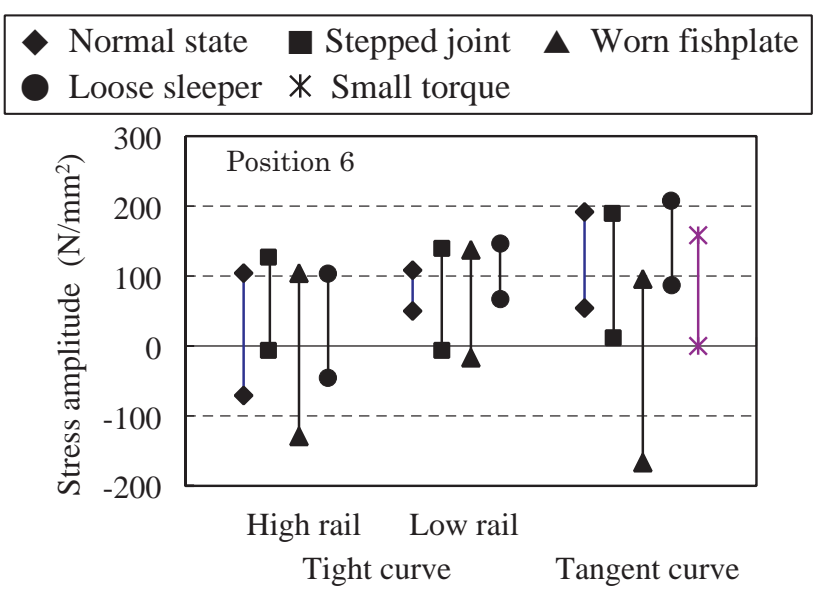

Fig. 11 Example of evaluated stresses

\section{Fatigue test of rails with holes}

\subsection{Test methods}

To estimate the fatigue life of jointed rails, it is needed to clarify the relation between stress amplitudes and the number of cycles of load application to the rail until it fractures. Fatigue tests of jointed rails were carried out, therefore, by bending rail specimens bored with two 400 mm-distant holes which were $24 \mathrm{~mm}$ in diameter (Fig.

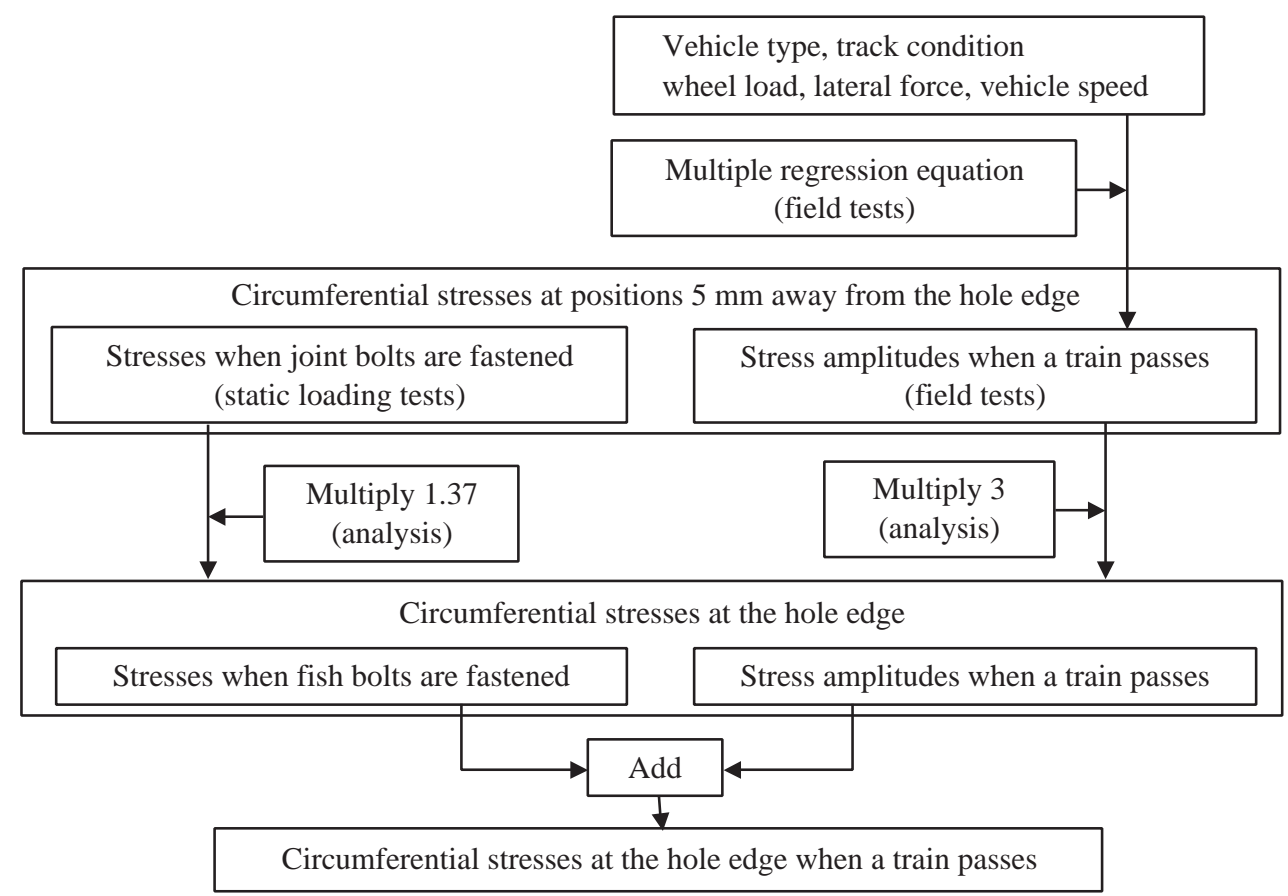

Fig. 10 Flow chart of procedure to evaluate stresses at the edge of bolt hole when a train passes $(50 \mathrm{kgN}$ rail) 


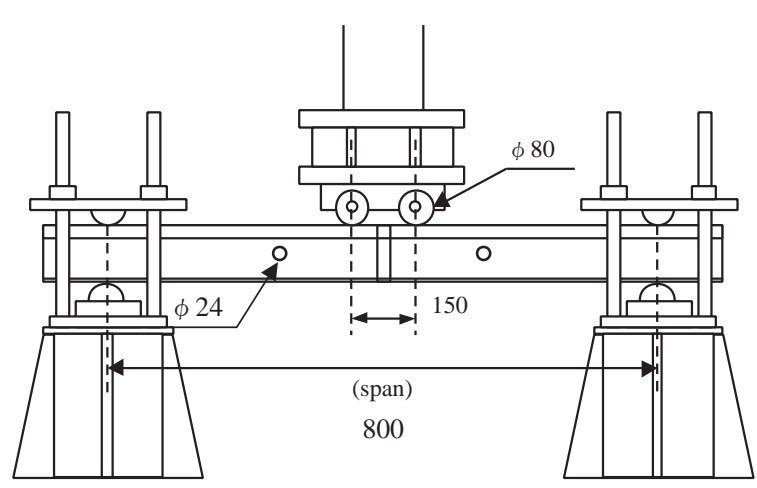

Fig. 12 Rail bending fatigue test set up

12). Stresses under loading were measured at the edge of hole in advance.

\subsection{Results}

Figure 13 shows a rail fractured in these tests. Cracks initiated at the hole edge and grew to 45 degree directions. It was similar to the typical fracture of jointed rails and the tests succeeded in reproducing the fatigue of jointed rails.

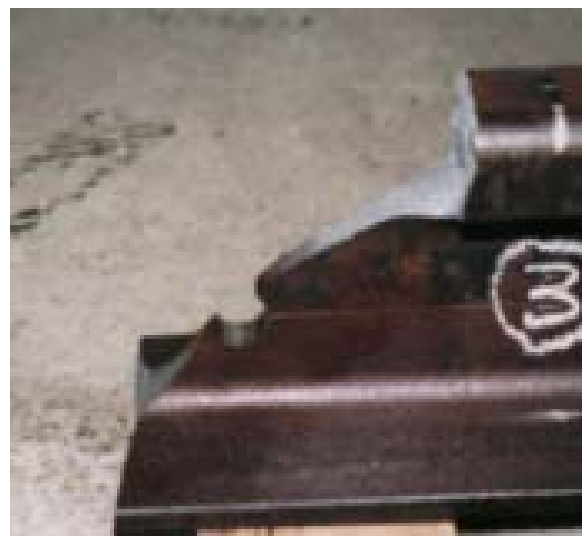

Fig. 13 Example of rail fractured in fatigue test

An S-N curve was obtained by the following methods. The mean fatigue strength was estimated for each number of cycles by applying Probit analysis using weighting coefficients suitable for small sample fatigue data sets. An S-N curve at the fracture probability of $50 \%$ was calculated by the weighted least squares method. The fatigue strength at each number of cycles was assumed to have a normal distribution and $\mathrm{S}-\mathrm{N}$ curve was assumed to pass the point of minimum fatigue strength. The data of fretting fatigue and fracture not initiating at holes were treated as non-fracture data and 10 data of actual rail breaking stress were used. Figure 14 shows the S-N curve whose fracture probability is $50 \%$.

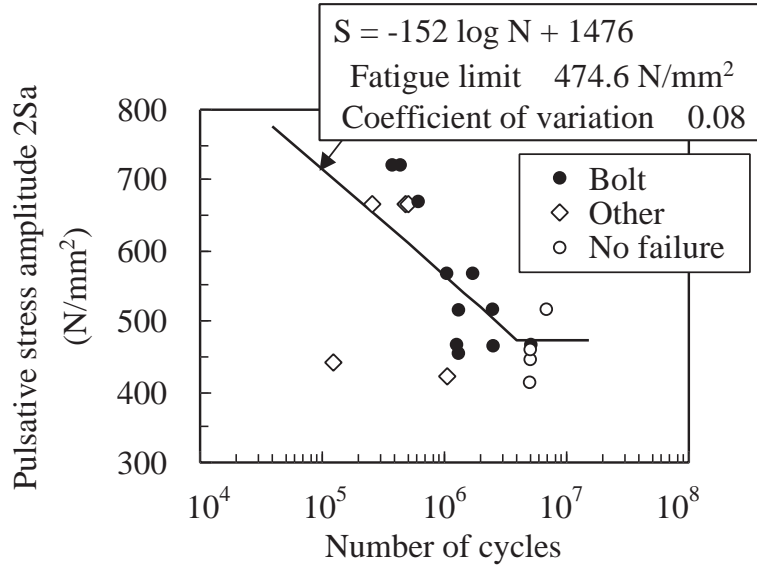

Fig. 14 S-N curve of jointed rail

\section{Evaluation of fatigue life of jointed rails}

The fatigue life was evaluated for different track conditions and vehicle types by substituting the estimated stress variation into the $\mathrm{S}-\mathrm{N}$ curve. Miner's rule was adopted and modified so that the slope of the S-N curve at the stress amplitude under the fatigue limit becomes half that at the amplitude over the fatigue limit. In the calculation, the standard deviation of stress amplitudes obtained from field tests was taken into account.

Figure 15 shows an example of evaluated fatigue life for $1 \%$ fracture probability. When the fatigue lives for different track conditions are compared, the lives under normal state and loose sleeper conditions, which were thousands MGT, were longer than those under other conditions. The fatigue life under the worn fishplate condition was as short as about $10 \mathrm{MGT}$. The lives of jointed rails used for locomotives on a tight curve were in most conditions shorter than those used for other types of cars because of their heavy weight. On the other hand, the lives used for limited expresses on a tangent curve in several conditions were shorter than those used for other types of cars because of their high speed. The lives of $60 \mathrm{~kg}$ rail with a large sec-

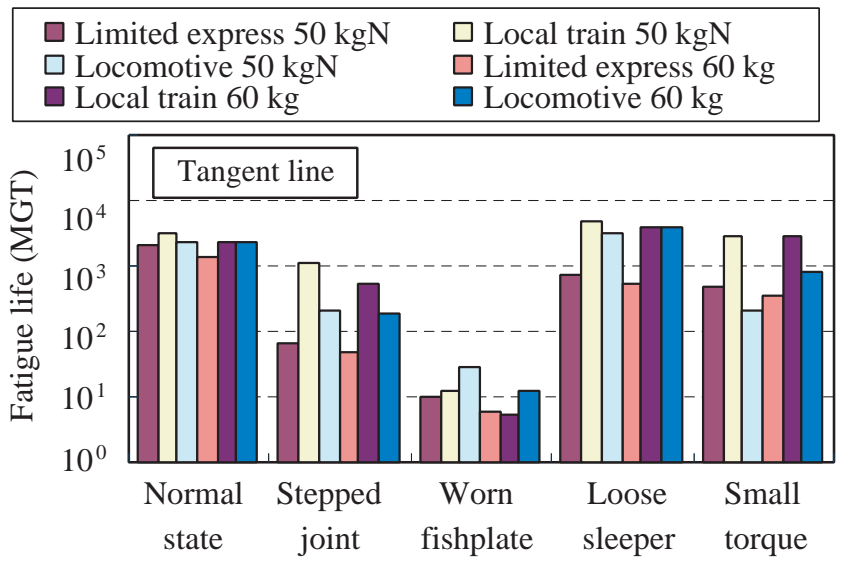

Fig. 15 Example of evaluated fatigue life 
tional modulus were shorter than those of $50 \mathrm{kgN}$ rail, since the evaluated stresses of $60 \mathrm{~kg}$ rail were larger than those of $50 \mathrm{kgN}$ rail.

\section{Conclusions}

To evaluate the fatigue life of jointed rails, stresses around fish bolt holes were clarified and a method to evaluate the fatigue life of the jointed rails was developed.

1. Static loading tests and field tests were carried out to measure the stresses around fish bolt holes. A tensile stress field in the vertical direction occurred when joint bolts were fastened. The maximum amplitudes of stresses occurred under a vertical load at 45-degree positions. The relationship between stress variations and vehicle speed, wheel load and lateral force was clarified from the results of a field test by multiple regression analysis. Static analyses deduced the relation between circumferential stresses at positions of $5 \mathrm{~mm}$ away and those at the edge of fish bolt hole. Based on these results, we established a method to evaluate the stresses at the edges of fish bolt holes when fish bolts were fastened and trains passed.

2. Bending fatigue tests using rails with holes were car- ried out to clarify the relation between stress amplitudes and the number of cycles of load application at fracture. Cracks initiated in the 45-degree directions at the edge of holes, therefore the tests succeeded in reproducing the fatigue of jointed rails. An S-N curve was obtained from the results.

3. As a result of this study, a method to evaluate the fatigue life of jointed rails was established. This method evaluates stresses for several conditions of jointed rail, vehicle type, vehicle speed, wheel load and lateral force. The fatigue life is calculated by applying stresses to the S-N curve.

\section{References}

1) Cannon, D. F., Sinclair, J., Sharpe, K. A.: "Improving the Fatigue Performance of Bolt Holes in Railway Rails by Cold Expansion," Proceedings of Fatigue, Corrosion Cracking, Fracture Mechanics \& Failure Analysis, International Conference \& Exposition, December 1985.

2) Satoh, Y., Sato, Y.: "Life of Rail (in Japanese)," Railway Technical Research Report, No.476, June 1965. 